Centre for Evidence Based Medicine, Nuffield Department of Primary Care Health Sciences, University of Oxford, Oxford

jeffrey.aronson@phc.ox.ac.uk Cite this as: BMJ 2021;375:n3111 http://dx.doi.org/10.1136/bmj.n3111 Published: 17 December 2021

\title{
When I use a word .... The Precautionary Principle: a definition
}

Many definitions of the Precautionary Principle omit two important ideas: that it applies only when the benefit to harm balance of a proposed intervention is unfavourable or uncertain and that the onus to prove that it is not unfavourable is on those who would advocate use of the intervention. The following proposed definition for healthcare interventions incorporates these two ideas: "The principle that if a healthcare intervention, pharmacological or non-pharmacological, may cause harm to the individual, the public, or the environment, the benefit to harm balance being unfavourable or uncertain, precautionary measures should be taken, and the burden of proving that the intervention is not harmful falls on those proposing that it be implemented."

Jeffrey K Aronson,

\section{Being precautionary}

Discussing therapeutic interventions a couple of weeks ago, ${ }^{1}$ I invoked the benefit:harm balance, and suggested three different forms of precaution:

1. When seeking benefit, administering an appropriate medication in an appropriate regimen.

2. When the benefit:harm balance is favourable, monitoring for possible unexpected harms or taking appropriate steps to prevent or minimise predictable harms.

3. When the benefit:harm balance is unclear or unfavourable, using precautionary measures.

The last of these is the Precautionary Principle, ${ }^{2}$ defined in the Oxford English Dictionary (OED) as "(originally and chiefly in environmental contexts) the principle that if the (long-term) consequences of an action are unknown, but have the potential to be harmful, the action should be avoided." ${ }^{3}$ Similar definitions can be found elsewhere. ${ }^{4}$

However, this definition omits two important features that are relevant to healthcare.

\section{A systematic review}

To discover how often the Precautionary Principle is discussed as a main topic in the bioscience literature, and to explore the ways in which it is defined, I searched three bioscience databases (PubMed, Medline, and EMBASE), looking for "precautionary principle" in the titles of publications; I found 393. Between 1989, when the term first appeared in any of the databases, ${ }^{5}$ and 1998 I found only 20 papers in all. However, the annual numbers then started to climb, reaching a maximum of 41 in 2004. Since then they have fallen, although there has again been a slight rise in the last few years; 2021 yielded 22 hits. The topics that have featured as the main concerns in these 393 sources are as follows:

The environment 107 (27.2\%)

[Non-pharmacological therapeutic interventions 59 $(15.0 \%)$

General topics 50 (12.7\%)

Public health 44 (11.2\%)

Ethics 26 (6.6\%)
Risk analysis/management 25 (6.4\%)

Dccupational medicine 23 (5.9\%)

Pharmacological interventions 18 (4.6\%)

Legal matters 13 (3.3\%)

[Statistics and epidemiology 11 (2.8\%)

Politics and economics 10 (2.5\%)

Philosophy 7 (1.8\%)

Discussion of the Precautionary Principle in the bioscience literature has been mostly devoted to environmental matters and public health in an environmental context. Its role in medical interventions has been discussed less often, and its role in the regulation of pharmacological interventions hardly at all.

Several criticisms have been levelled against the Precautionary Principle. For example: that it is ill defined and therefore too vague and ambiguous to be of use ${ }^{6-8}$; that it is absolutist ${ }^{9}$ and does not prescribe the extent to which caution should be exerted ${ }^{10}$; that it paradoxically increases risk-taking behaviour $^{11}$; and that excess precaution can stifle innovation. ${ }^{12}$ Robust defences against these charges have been mounted. ${ }^{13-15}$ Furthermore, some of them can be met by improving the definition.

Here therefore I propose a definition, primarily applicable to pharmacological interventions, but which might be useful in other circumstances. It is mainly based on previous definitions and considering how the processes involved actually operate from practical examples.

\section{The benefit:harm balance}

The $O E D$ definition suggests that if there is any possible harm the Precautionary Principle should be applied. That cannot be the case. Virtually any therapeutic intervention that we use may cause harms. The appropriate criterion is the benefit:harm balance. If we know it to be favourable, we can introduce the intervention with varying degrees of caution, depending on our expectation of the possibility of harm, perhaps adding some preventive measure. It is when the possibility of harm exceeds that of benefit that we must pause, taking into account the chance and quality of the benefit, the 
chance and possible intensity of the harm, and the chance and nature of harm from not intervening.

A hint of this comes from a definition of the precautionary principle in European law: "an approach to risk management whereby if there is the possibility that a given policy or action might cause harm to the public or the environment and if there is still no scientific consensus on the issue, the policy or action in question should not be pursued." ${ }^{16}$ In this definition the phrase "if there is still no scientific consensus" points to uncertainty about the benefit:harm balance, even though it does not state it explicitly.

The benefit:harm balance in the population is routinely assessed by regulatory authorities when considering aspects of marketing authorisation and by guidelines committees. It will generally be assessed in the population as a whole, adducing the best available evidence. However, subgroups of susceptible individuals are often identified in whom the benefit:harm balance may not be favourable, and advice about the use of the intervention will include caveats about cautions or contraindications in such groups. For example, the antiretroviral drug abacavir is contraindicated in people with a specific genotype, HLA B` 5701 , but it may be useful in others. Here, too, the Precautionary Principle is relevant.

Lack of consensus about the benefit:harm balance implies that it is uncertain and that some might argue in favour of the intervention. This brings me to the second feature missing from the $O E D$ definition.

\section{Who decides?}

The Wingspread Consensus Statement on the Precautionary Principle, ${ }^{17}$ published after a conference in January 1998, which dealt with the release and use of toxic substances, the exploitation of resources, and physical alterations of the environment, asserted that "[although] human activities may involve hazards, people must proceed more carefully than has been the case in recent history. Corporations, government entities, organizations, communities, scientists and other individuals must adopt a precautionary approach to all human endeavors. Therefore, it is necessary to implement the Precautionary Principle: When an activity raises threats of harm to human health or the environment, precautionary measures should be taken even if some cause and effect relationships are not fully established scientifically. ... In this context the proponent of an activity, rather than the public bears the burden of proof."

This statement addresses the question of who decides whether an intervention should be implemented or avoided when the benefit:harm balance is uncertain and possibly unfavourable. It makes it clear that it is for those who would implement an intervention to demonstrate that the benefit:harm balance is not unfavourable. It has been a hallmark of some interventions that have been inappropriately touted during the current pandemic that those who have evangelistically supported them have paid scant attention, not only to the quality of the evidence supporting the putative benefits, but also to the potential harms, ignoring them or dismissing them as unimportant in the absence of evidence.

\section{A proposed definition}

This leads me to propose the following definition of the Precautionary Principle, as applied to healthcare interventions:

Precautionary principlen. The principle that if a healthcare intervention, pharmacological or non-pharmacological, may cause harm to the individual, the public, or the environment, the benefit to harm balance being unfavourable or uncertain, precautionary measures should be taken, and the burden of proving that the intervention is not harmful falls on those proposing that it be implemented" [Latin, praecautio via French précaution; Latin, principium via French principe]

Notes on the definition: "harm" includes any harm that may arise from using the intervention and any harms that may arise from not intervening; "precautionary measures" include avoidance of the intervention or introduction of a preventive measure.

\section{Competing interest: None declared.}

Aronson JKclinical pharmacologist. When I use a word. . . . Taking therapeutic care. BMJ 2021;375:n3010. doi: 10.1136/bmj.n3010. pmid: 34862174

2 Aronson JKclinical pharmacologist. When I use a word. ... The Precautionary Principle: a brief history. BMJ 2021;375:n3059. doi: 10.1136/bmj.n3059. pmid: 34893515

3 precautionary, adj. and n.". OED Online. December 2021. Oxford University Press. https://www.oed.com/view/Entry/149565?redirectedFrom=precautionary. UNESCO World Commission on the Ethics of Scientific Knowledge and Technology(COMEST). The Precautionary Principle. World Commission on the Ethics of Scientific Knowledge and Technology (COMEST). UNESCO, 2005.

5 Ross A. Nuvan use in salmon farming. The antithesis of the precautionary principle. Mar Pollut Bull 1989;20:372-4doi: 10.1016/0025-326X(89)90313-5.

6 Jordan A, O'Riordan T. The precautionary principle in contemporary environmental policy and politics. In: Raffensberger C, Tickner J, eds. Protecting Public Health and the Environment: Implementing the Precautionary Principle. Island Press, 1999: 15-35.

7 Turner D, Hartzell L. The lack of clarity in the precautionary principle. Environ Values 2004;13:449-60doi: 10.3197/0963271042772604.

8 Bodansky D. Scientific uncertainty and the Precautionary Principle. Environment 1991;33:4-5doi: 10.1080/00139157.1991.9929978.

9 Manson N. The precautionary principle, the catastrophe argument, and Pascal's wager. Ends and Means 1999:4:12-6.

10 Bodansky D. Scientific uncertainty and the precautionary principle. Environment 1991:33:4-6doi: 10.1080/00139157.1991.9929978.

11 Nollkaemper A. "What you risk reveals what you value", and other dilemmas encountered in the legal assaults on risks. In: Freestone D, Hey E, eds. The Precautionary Principle and International Law. Kluwer Law International, 1996: 73-94.

12 Sloane P. How the innovation principle supplements and balances the precautionary principle. 31 May 2017. https://www.innovationmanagement.se/2017/05/31/how-the-innovation-principle supplements-and-balances-the-precautionary-principle.

13 Sandin P, Peterson M, Hansson S, Rudén C, Juthe A. Five charges against the precautionary principle. J Risk Res 2002;5:287-99doi: 10.1080/13669870110073729.

14 Ahteensuu M. Defending the precautionary principle against three criticisms. TRAMES 2007; 11(61/56): 366-81.

15 Osimani B. The precautionary principle in the pharmaceutical domain: a philosophical enquiry into probabilistic reasoning and risk aversion. Health Risk Soc 2013;15:123-43doi: 10.1080/13698575.2013.771736.

16 EUR-Lex. Glossary of summaries. Precautionary principle. https://eur-lex.europa.eu/summary/glos sary/precautionary_principle.html.

17 Wingspread Statement on the Precautionary Principle. http://www.gdrc.org/u-gov/precaution3.html. 